\title{
Teaching operative cardiac surgery in the era of increasing patient complexity: Can it still be done?
}

\author{
George Tolis, Jr, MD, Philip J. Spencer, MD, Jordan P. Bloom, MD, Serguei Melnitchouk, MD, \\ David A. D’Alessandro, MD, Mauricio A. Villavicencio, MD, and Thoralf M. Sundt III, MD
}

\section{ABSTRACT}

Objective: Teaching the next generation operative cardiac surgery while maintaining the highest level of patient care is an ever-increasing challenge given the growing proportion of patients with multiple comorbidities, the loss of more straightforward cases to percutaneous interventions, and the pressure of public reporting. No study to date has compared the outcomes of similar cases performed entirely ("skin-to-skin") by the resident with those performed entirely by the staff to confirm the safety of this practice.

Methods: A total of 100 consecutive cardiac cases performed skin-to-skin by the resident (group $\mathrm{R}$ ) were matched by procedure 1:1 to nonconsecutive cases performed by a single attending surgeon (group A). Patients were excluded from the analysis if there was overlap in any portion of the procedure by the trainee or the attending.

Results: Patients in group A were similar to those in group $\mathrm{R}$ with respect to age, gender, body mass index, American Society of Anesthesiologists classification, left ventricular ejection fraction, and diabetes mellitus. Mean operative times were longer in group R (4.6 vs 2.7 hours, $P<.001$ ), as were cardiopulmonary bypass times (96 vs 50 minutes, $P<.001)$ and aortic crossclamp times (78 vs 39 minutes, $P<.001)$. There were no significant differences in red blood cell transfusions, reexplorations, stroke, length of stay, or wound infections. There were no in-hospital or 30-day deaths.

Conclusions: Our data indicate that trainees can be educated in operative surgery under the current paradigm, despite longer operative times, without sacrificing outcome quality. It is reasonable to expect academic programs to continue providing trainees significant experience as primary operating surgeons. (J Thorac Cardiovasc Surg 2018;155:2058-65)

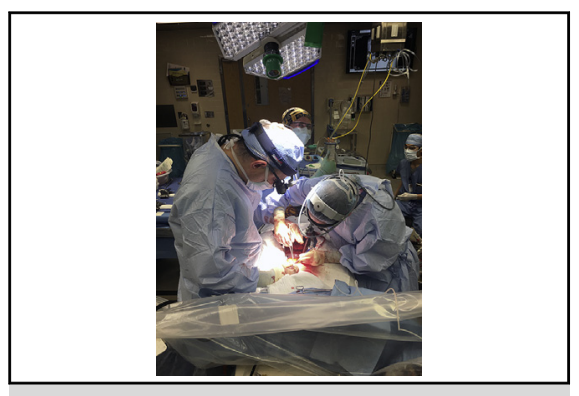

Dr Tolis and a cardiac surgery resident at Massachusetts General Hospital.

\section{Central Message}

An organized approach to cardiac surgical training can safely produce well-trained surgeons in the current era. Academic programs should continue providing trainees experience as primary surgeons.

\section{Perspective}

Increased patient complexity combined with resident work hour regulations and public reporting of outcomes and complications has compromised the training experience of cardiac surgical residents. This study shows that with a carefully planned approach to surgical education, residents can be appropriately trained while patients can continue receiving excellent medical care.

See Editorial Commentary page 2066.
Despite the introduction and acceptance of less-invasive access techniques such as transcatheter aortic valve replacement (AVR) and mitral clip procedures over the past few

From the Division of Cardiac Surgery, Massachusetts General Hospital, Boston, Mass.

Read at the 97th Annual Meeting of The American Association for Thoracic Surgery, Boston, Massachusetts, April 29-May 3, 2017.

Date of Institutional Review Board approval: April 21, 2016. Institutional Review Board approval number: 2016P000592.

Received for publication April 14, 2017; revisions received Nov 2, 2017; accepted for publication Nov 17, 2017; available ahead of print Feb 10, 2018.

Address for reprints: George Tolis, Jr, MD, Division of Cardiac Surgery, 55 Fruit St, Cox 630, Massachusetts General Hospital, Boston, MA 02114 (E-mail: gtolis@ mgh.harvard.edu).

0022-5223/\$36.00

Copyright (c) 2018 by The American Association for Thoracic Surgery

https://doi.org/10.1016/j.jtcvs.2017.11.109 years, cardiac surgery has largely remained a traditional "open" surgical specialty. The majority of cardiac operations are still performed through a median sternotomy or a right thoracotomy requiring advanced open surgical skills. Surgical staples and anastomotic devices have found limited applicability in adult cardiac surgery and have been largely abandoned. At the same time, other surgical

Scanning this QR code will take you to a supplemental video. To view the AATS Annual Meeting Webcast, see the URL next to the webcast thumbnail. 

Abbreviations and Acronyms
ACC = aortic crossclamp
AVR $=$ aortic valve replacement
$\mathrm{CABG}=$ coronary artery bypass grafting
$\mathrm{CPB}=$ cardiopulmonary bypass
MVR = mitral valve replacement
STS = Society of Thoracic Surgeons

parameters. ${ }^{11-13}$ The purpose of this study was to compare postoperative outcomes of 2 similar surgical patient cohorts whose operations were performed entirely by an attending surgeon or by a physician in training. By doing so, we hoped to determine if the inefficiencies associated with resident training affect clinical outcomes and to further drill down on appropriate patient selection for resident training. We think that observing residents operating skin-to-skin is the ultimate assessment of competency and readiness for surgical practice (Video 1).

\section{MATERIALS AND METHODS Patient Selection and Data Collection}

This study was approved by the Partners Human Research Committee's Institutional Review Board for human research to meet ethical and legal requirements. From July 2014 to December 2016, Dr Tolis completed a total of 642 pump cases, either as teaching surgeon or primary surgeon. The breakdown of these cases is as follows: isolated coronary artery bypass grafting (CABG) (321), isolated AVR (84), isolated mitral valve replacement (MVR) (8), AVR/CABG (64), MVR/CABG (3), AVR/MVR (4), mitral valve repair (12), mitral valve repair/CABG (17), and other (129). A prospective longitudinal database was created capturing comprehensive data for all patients undergoing cardiac operations by Dr Tolis at our institution. Consecutive cases done skin-to-skin by the resident surgeon during the study period with attending supervision were matched by specific operative procedure $1: 1$ with cases done skin-to-skin by the same attending surgeon. A 1:1 matching was achieved once the resident cases reached a total of 100. Because we collected our data prospectively, in almost all categories there were fewer attending alone cases, necessitating the attending to perform several cases in each category himself to achieve equal numbers in all categories and eventually achieve $1: 1$ matching with the resident alone cases. All cases were performed at the Massachusetts General Hospital main campus.

\section{Training}

The cardiothoracic training program at the Massachusetts General Hospital consists of both rotating general surgery residents and full-time cardiothoracic residents who have completed general surgery training. All cases done skin-to-skin by resident surgeons were done so by the 8 full-time cardiothoracic residents who rotated with Dr Tolis during the study period. Of the 8 residents, 4 performed skin-to-skin cases during both full years of their training, whereas the other 4 only performed skin-to-skin cases during the second year of their training.

Before being allowed to perform an operation skin-to-skin, the residents had displayed competency in performing each individual step of the operation during the earlier part of their training (eg, opening, harvesting conduits, cannulating, constructing distal and proximal anastomoses). This had been significantly enhanced after adoption of the "apprenticeship model," which we implemented in our program in 2013, where a resident would be assigned to a specific attending for a 2- to 3-month block to increase the level of responsibility allowed to the resident and enhance the resident's experience.

\section{Definitions}

Cases were considered skin-to-skin if the operating surgeon completed each of the following steps of the operation from the right side of the operating table:

\section{Common steps.}

1. Opening of skin, soft tissues, sternum, and pericardium.

2. Cannulation for cardiopulmonary bypass (CPB).

3. Placement of aortic crossclamp (ACC). many preoperative, perioperative, and postoperative 


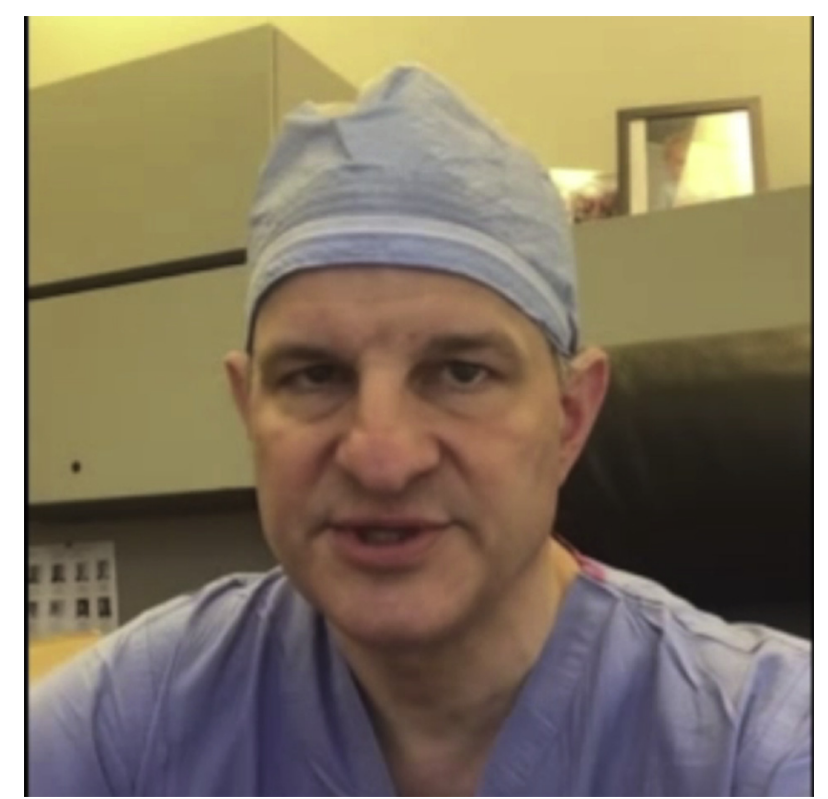

VIDEO 1. Dr George Tolis discussing a brief overview of the Massachusetts General Hospital study on teaching residents operative cardiac surgery. Video available at: http://www.jtcvsonline.org/article/S00225223(18)30068-0/fulltext.

4. Completion of the procedure specific steps (below).

5. Decannulation and separation from CPB.

6. Achieving hemostasis and closure of sternum, soft tissues, and skin.

\section{CABG-specific steps.}

1. Harvesting the arterial conduit(s).

2. Identification, dissection, and opening of coronary arteries.

3. Completion of both proximal and distal anastomoses for every bypass graft.

\section{AVR/MVR-specific steps. \\ 1. Performing the aortotomy/atriotomy. \\ 2. Resection/reconstruction of native valve. \\ 3. Placing every annular suture. \\ 4. Tying every knot. \\ 5. Closing the aortotomy/atriotomy.}

If the attending surgeon had to intervene and complete one of these steps, the case was excluded from our analysis. There were several cases that were intended to be resident cases but were converted to mixed (attending and resident cases) because the attending surgeon had to intervene at some point during the operation. Typical reasons that this scenario would take place were (1) dense pericardial adhesions making cannulation and identification of coronary arteries difficult, (2) excess annular calcium in a mitral or AVR procedure necessitating attending involvement, (3) leaking of a distal or proximal anastomosis requiring taking down the anastomosis and reconstructing it, or (4) distorted anatomy of the heart and great vessels making it technically difficult to perform a standard cannulation. All these cases were considered "mixed" cases (both attending and resident involvement) and were not included in this study. During our original analysis of the data, we did not identify any complications in these cases (eg, death, stroke, wound infection) that we could directly attribute to this "conversion."

There are cases that become "mixed" or even "attending only" simply because of timing issues (eg, starting late in the day, need to complete $>2$ cases in 1 day) even though they could be easily done entirely by a trainee. When this happened, these cases were not included in this study even though in many of them the bulk of the case was done by the resident. We decided to keep a strict definition of a "resident" case to eliminate any "judgment" issues as to what constitutes a resident case.

\section{Statistical Analysis}

All statistical analysis was performed with Stata/SE 12.1 (StataCorp, LP, College Station, Tex). Continuous data, which were normally distributed, were expressed as means with standard deviations, and non-normally distributed data were expressed as medians with interquartile ranges. Categoric data were expressed as numbers and percentages. Student $t$ test or Wilcoxon ranksum tests were used where appropriate for continuous variables, and the chisquare test was used where appropriate for categoric variables. All tests were performed 2 sided. Normality of the data was assessed using histograms, skewness, kurtosis, or the Shapiro-Wilk test.

\section{RESULTS}

A total of 200 cardiac surgery cases were analyzed, which were performed between July 2014 and December 2016. A total of 100 consecutive cases performed by the resident were matched 1:1 with 100 nonconsecutive cases performed by the attending surgeon (G.T.) during the same time interval. Within that timeframe, the attending surgeon performed a total of 642 cases. One case performed by the resident (isolated tricuspid valve repair) could not be matched with an equivalent attending case and was excluded from the study. Of note, that patient made an uneventful recovery.

\section{Preoperative Characteristics}

The preoperative characteristics of the patients in the attending and resident groups are shown in Table 1. There were no statistically significant differences in age, sex, body mass index, American Society of Anesthesiologists score, left ventricular ejection fraction, or diabetes mellitus. Patients in the attending group had higher Society of Thoracic Surgeons (STS) predicted mortality scores when compared with patients in the resident group $(1.55 \%$ vs $1.22 \%, P=.04)$. To determine the cause of this difference, we separately analyzed all variables used to determine the STS score and found it was largely due to differences in 3 predictors: age more than 66 years $(64 \%$ vs $49 \%$, $P=.03)$, use of intra-aortic balloon pump (10\% vs $4 \%$, $P=.1$ ), and case status (elective, $23 \%$ vs $39 \%$; urgent, $74 \%$ vs $60 \%$; and emergency, $3 \%$ vs $1 \%, P=.04$ ). Trainees in the resident group were further along in training than those in the attending group (postgraduate year $7.2 \mathrm{vs}$ $5.7, P<.001$ ). This is not surprising given that the more senior level residents are entrusted with and expected to perform the technical aspects of the operation, albeit under supervision.

\section{Types of Operations}

The operative details and cases are shown in Table 2. The caseload included isolated CABG procedures including 2-vessel CABG $(\mathrm{n}=34)$, 3-vessel CABG $(\mathrm{n}=34)$, 
TABLE 1. Preoperative characteristics for operations performed skin-to-skin by the attending surgeon or the resident surgeon

\begin{tabular}{|c|c|c|c|}
\hline Variable & $\begin{array}{l}\text { Attending } \\
\text { surgeon } \\
(\mathbf{n}=\mathbf{1 0 0})\end{array}$ & $\begin{array}{l}\text { Resident } \\
\text { surgeons } \\
(\mathbf{n}=\mathbf{1 0 0})\end{array}$ & $\begin{array}{c}P \\
\text { value }\end{array}$ \\
\hline Age (y) Mean, SD & $69.2(10.4)$ & $67(9.3)$ & .1 \\
\hline Range & $43-91$ & $47-89$ & \\
\hline Female no. $(\%)$ & $20(20)$ & $19(19)$ & .9 \\
\hline $\begin{array}{l}\text { BMI }\left(\mathrm{kg} / \mathrm{m}^{2}\right) \text { Mean, SD } \\
\text { Range }\end{array}$ & $\begin{array}{r}28.6(5.3) \\
17.3-47.1\end{array}$ & $\begin{array}{l}29.5(5.7) \\
18.7-55.2\end{array}$ & .2 \\
\hline \multicolumn{4}{|l|}{ ASA } \\
\hline $\begin{array}{l}\text { Median } \\
\text { IQR }\end{array}$ & $\begin{array}{c}3 \\
3-4\end{array}$ & $\begin{array}{c}3 \\
3-4\end{array}$ & .7 \\
\hline $\begin{array}{l}\text { Ejection fraction } \\
\qquad(\mathrm{mL} / \mathrm{min}) \\
\text { mean, SD }\end{array}$ & $55.9,13.9$ & $58,12.9$ & .3 \\
\hline Diabetes mellitus & $30(30)$ & $39(39)$ & .2 \\
\hline \multicolumn{4}{|l|}{$\begin{array}{l}\text { STS predicted mortality } \\
\quad(\%)\end{array}$} \\
\hline Median & 1.55 & 1.22 & .04 \\
\hline IQR & $0.9-3.2$ & $0.5-2.2$ & \\
\hline IABP no. (\%) & $10(10)$ & $4(4)$ & .1 \\
\hline Inserted preoperatively & $9(90)$ & $1(25)$ & .02 \\
\hline $\begin{array}{l}\text { Inserted } \\
\text { intraoperatively }\end{array}$ & $1(10)$ & $3(75)$ & .02 \\
\hline $\begin{array}{l}\text { Inserted } \\
\text { postoperatively }\end{array}$ & 0 & 0 & \\
\hline Age $>66(y)$ no. $(\%)$ & $64(64)$ & 49 (49) & .03 \\
\hline \multicolumn{4}{|l|}{ Case status no. ( $\%)$} \\
\hline Elective & $23(23)$ & $39(39)$ & .04 \\
\hline Urgent & $74(74)$ & $60(60)$ & .04 \\
\hline Emergency & $3(3)$ & $1(1)$ & .04 \\
\hline $\begin{array}{l}\text { Postgraduate year of } \\
\text { trainee Mean, SD }\end{array}$ & $5.7,1.4$ & $7.2,0.7$ & $<.001$ \\
\hline
\end{tabular}

SD, Standard deviation; $B M I$, body mass index; $A S A$, American Society of Anesthesiologists; IQR, interquartile range; STS, Society of Thoracic Surgeons; IABP, intraaortic balloon pump.

4-vessel CABG $(n=10)$, and 5-vessel CABG $(n=4)$ in each group. There were 10 isolated AVRs, 7 AVR/CABG operations, and $1 \mathrm{MVR} / \mathrm{CABG} \times 3$ operation in each group. Table 2 demonstrates this breakdown and the differences in total operative time ( 2.7 vs 4.6 hours, $P<.001$ ), CPB times (50 vs 96 minutes, $P<.001$ ), and ACC times (39 vs 78 minutes, $P<.001)$.

\section{Operative Details}

As demonstrated in Figure 1 and Table 3, operations performed by the attending surgeon were significantly shorter in total operative time, $\mathrm{CPB}$ time, and ACC time than the operations performed by resident surgeons. Intraoperative blood product use was not different between groups. Total operative time in hours were CABG $\times 22.3$ versus 3.9 $(P<.001)$, CABG $\times 32.7$ versus $4.8(P<.001)$,
TABLE 2. Operative details of operations performed skin-to-skin by the attending surgeon or the resident surgeon

\begin{tabular}{lccc}
\hline \multicolumn{1}{c}{ Variable } & $\begin{array}{c}\text { Attending } \\
\text { surgeon } \\
(\mathbf{n}=\mathbf{1 0 0})\end{array}$ & $\begin{array}{c}\text { Resident } \\
\text { surgeons } \\
(\mathbf{n = 1 0 0})\end{array}$ & $\begin{array}{c}\boldsymbol{P} \\
\text { value }\end{array}$ \\
\hline Procedures & & & \\
CABG $\times 2$ no. & 34 & 34 & \\
CABG $\times 3$ no. & 34 & 34 & \\
CABG $\times 4$ no. & 10 & 10 & \\
CABG $\times 5$ no. & 4 & 4 & \\
AVR no. & 10 & 10 & \\
AVR/CABG no. & 7 & 7 & \\
MVR/CABG $\times 3$ no. & 1 & 1 & \\
Operative time (h) Mean, & $2.7,0.6$ & $4.6,1$ & \\
SD & & & \\
Range & $1.6-4.7$ & $2.8-8.5$ & \\
CPB time (min) & & & \\
Median & 50 & 96 & \\
IQR & $41-60$ & $75-110$ & \\
\hline ACC time (min) & & & \\
Median & 39 & 78 & $<.001$ \\
IQR & $30-49$ & $57-93$ & \\
pRBC transfusion no. $(\%)$ & $17(17)$ & $12(12)$ & \\
\hline CABG Con & & & \\
\hline
\end{tabular}

$C A B G$, Coronary artery bypass grafting; $A V R$, aortic valve replacement; $M V R$, mitral valve replacement; $S D$, standard deviation; $C P B$, cardiopulmonary bypass; $I Q R$, interquartile range; $A C C$, aortic crossclamp; $p R B C$, packed red blood cells.

CABG $\times 43.3$ versus $5.4(P<.001)$, CABG $\times 53.7$ versus $5.8(P=.02)$, AVR 2.2 versus $3.9(P<.001)$, AVR/CABG 3.5 versus $5.8(P=.04)$, and MVR/CABG $\times 33.6$ versus $5.8(P=.3)$. The CPB times for the attending surgeon versus the resident groups were $\mathrm{CABG} \times 238$ versus $69 \mathrm{mi}-$ nutes $(P<.001)$, CABG $\times 350$ versus 97 minutes $(P<.001), \mathrm{CABG} \times 463$ versus 113 minutes $(P<.001)$, CABG $\times 583$ versus 144 minutes $(P=.02)$, AVR 59 versus 104 minutes $(P<.001)$, AVR/CABG 91 versus 122 minutes $(P=.003)$, and MVR/CABG $\times 386$ versus 140 minutes $(P=.3)$. A similar trend was seen for ACC times with $\mathrm{CABG} \times 228$ versus 53 minutes $(P<.001), \mathrm{CABG} \times 3$ 40 versus 78 minutes $(P<.001)$, CABG $\times 452$ versus 95 minutes $(P<.001), \mathrm{CABG} \times 570$ versus 115 minutes $(P=.02)$, AVR 47 versus 89 minutes $(P<.001)$, AVR/ CABG 78 versus 103 minutes $(P=.003)$, and MVR/ CABG $\times 368$ versus $140(P=.3)$.

\section{Postoperative Outcomes/Complications}

Length of stay was equivalent between the groups at a median of 6 days. There were 4 cerebrovascular accidents, 2 in each group. We had 5 superficial incisional wound infections (requiring antibiotics or incision and drainage), 3 in the attending group and 2 in the resident group $(P=.7)$, and 1 deep sternal wound infection in the attending group (requiring sternal debridement and pectoralis flap) $(P=.3)$. The patient requiring a flap was a 68 -year-old woman with uncontrolled diabetes and a nonhealing 
Total Operative Time

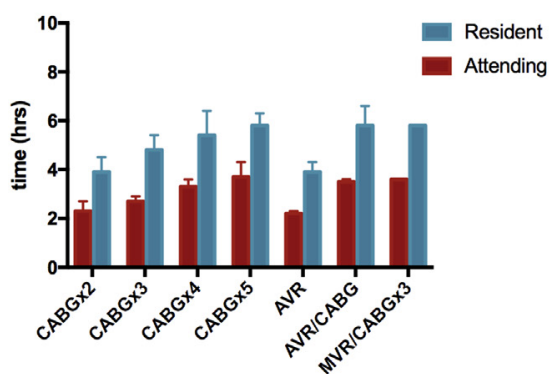

Cardiopulmonary Bypass Time

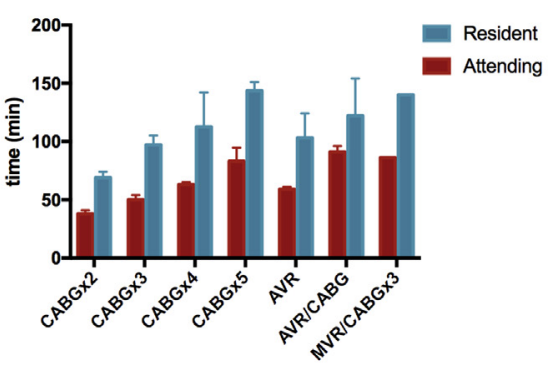

Aortic Cross-clamp Time

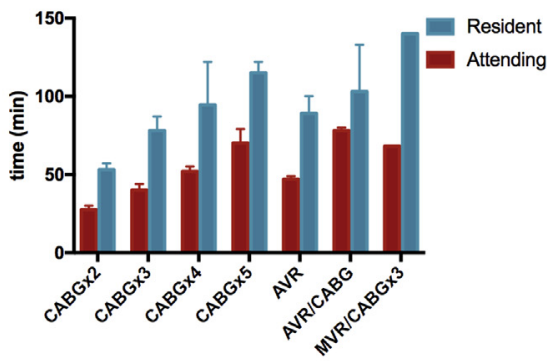

FIGURE 1. Comparison of CPB time and aortic crossclamp time between resident and attending groups. CABG, Coronary artery bypass grafting; $A V R$, aortic valve replacement; $M V R$, mitral valve replacement.

lower-extremity wound who needed urgent revascularization for unstable angina. Three patients required reoperations within 24 hours for postoperative bleeding, 2 in the attending group and 1 in the resident group $(P=.6)$. There were 9 readmissions within 30 days in the attending group and no readmissions in the resident group $(P=.002)$ (Table 4).

TABLE 3. Procedure-specific results of operations performed skin-toskin by the attending surgeon or the resident surgeon

\begin{tabular}{|c|c|c|c|}
\hline & $\begin{array}{l}\text { Attending } \\
\text { surgeon }\end{array}$ & $\begin{array}{l}\text { Resident } \\
\text { surgeon }\end{array}$ & $\begin{array}{c}P \\
\text { value }\end{array}$ \\
\hline \multicolumn{4}{|c|}{$\begin{array}{l}\text { Operative time (h) Median } \\
\text { (IQR) }\end{array}$} \\
\hline $\mathrm{CABG} \times 2$ & $2.3(2-2.7)$ & $3.9(3.8-4.5)$ & $<.001$ \\
\hline $\mathrm{CABG} \times 3$ & $2.7(2.5-2.9)$ & $4.8(4.4-5.4)$ & $<.001$ \\
\hline $\mathrm{CABG} \times 4$ & $3.3(2.9-3.6)$ & $5.4(5.1-6.4)$ & $<.001$ \\
\hline $\mathrm{CABG} \times 5$ & $3.7(3.2-4.3)$ & $5.8(5.4-6.3)$ & .02 \\
\hline AVR & $2.2(2-2.3)$ & $3.9(3.5-4.3)$ & $<.001$ \\
\hline AVR/CABG & $3.5(2.8-3.6)$ & $5.8(3.6-6.4)$ & .04 \\
\hline $\mathrm{MVR} / \mathrm{CABG} \times 3$ & 3.6 & 5.8 & .3 \\
\hline \multicolumn{4}{|c|}{$\begin{array}{l}\text { CPB time (min) Median } \\
\text { (IQR) }\end{array}$} \\
\hline $\mathrm{CABG} \times 2$ & $38(33-41)$ & 69 (64-76) & $<.001$ \\
\hline $\mathrm{CABG} \times 3$ & $50(46-54)$ & 97 (87-104) & $<.001$ \\
\hline $\mathrm{CABG} \times 4$ & $63(61-65)$ & $113(102-142)$ & $<.001$ \\
\hline $\mathrm{CABG} \times 5$ & $83(79-95)$ & $144(136-151)$ & .02 \\
\hline AVR & $59(52-60)$ & $104(100-124)$ & $<.001$ \\
\hline AVR/CABG & $91(78-96)$ & $122(113-154)$ & .003 \\
\hline $\mathrm{MVR} / \mathrm{CABG} \times 3$ & 86 & 140 & .3 \\
\hline \multicolumn{4}{|c|}{$\begin{array}{l}\text { ACC time (min) Median } \\
\text { (IQR) }\end{array}$} \\
\hline $\mathrm{CABG} \times 2$ & $28(25-30)$ & $53(49-57)$ & $<.001$ \\
\hline $\mathrm{CABG} \times 3$ & $40(37-43)$ & $78(66-87)$ & $<.001$ \\
\hline $\mathrm{CABG} \times 4$ & $52(50-55)$ & $95(85-122)$ & $<.001$ \\
\hline $\mathrm{CABG} \times 5$ & $70(66-79)$ & $115(103-122)$ & .02 \\
\hline AVR & $47(40-49)$ & $89(84-100)$ & $<.001$ \\
\hline AVR/CABG & $78(63-80)$ & $103(96-133)$ & .003 \\
\hline MVR/CABG $\times 3$ & 68 & 140 & .3 \\
\hline
\end{tabular}

$I Q R$, Interquartile range; $C A B G$, coronary artery bypass grafting; $A V R$, aortic valve replacement; $M V R$, mitral valve replacement; $C P B$, cardiopulmonary bypass; $A C C$, aortic crossclamp.

\section{DISCUSSION}

The findings of this study demonstrate that cardiothoracic residents in a busy academic center were offered a solid operative experience as primary surgeons without compromising the quality of care delivered to patients. Resident training required a significant time commitment by the attending staff as demonstrated by the near doubling of the CPB and crossclamp times, as well as the overall duration of the operations.

This analysis is unique when compared with previously published reports. This study is the first in the literature to compare postoperative outcomes of 2 case-matched groups of patients undergoing a variety of open cardiac operations performed entirely ("skin-to-skin") by an attending surgeon or by a trainee under attending supervision. By excluding any case in which even minimal crossover of operative responsibilities between trainee and attending took place, we eliminated any ambiguity about what constitutes "doing a case," which can be interpreted in many ways and removed a major confounding factor that may bias our conclusions when it comes to comparing outcomes between the 2 groups.

During this 30-month interval, the attending surgeon performed 625 cases. The residents performed 100 cases, $16 \%$ of the attending's total operative volume. Another 213 cases $(34 \%)$ were done by the attending skin-to-skin, with the remaining 312 cases $(50 \%)$ performed by both. The usual reasons why the attending would perform a case skin-to-skin were case complexity (eg, poor targets, small and heavily calcified aortic root), acuity or presence of comorbidities, lack of an appropriate assistant (eg, physician assistant, nurse practitioner), patient/family request, or late start time.

The preoperative characteristics of the 2 groups demonstrate that the attending group was more likely to include older and sicker patients, as well as patients requiring an urgent/emergency operation or intra-aortic balloon pump support. In addition, the postgraduate year of the trainee had a statistically significant impact on the attending's decision to allow the trainee to perform the operation. It should not be surprising that there was intentional bias built into the 
TABLE 4. Postoperative results of operations performed skin-to-skin by the attending surgeon or the resident surgeons

\begin{tabular}{lccc}
\hline \multicolumn{1}{c}{ Variable } & $\begin{array}{c}\text { Attending } \\
\text { surgeon } \\
(\mathbf{n = 1 0 0 )}\end{array}$ & $\begin{array}{c}\text { Resident } \\
\text { surgeons } \\
(\mathbf{n = 1 0 0})\end{array}$ & P value \\
\hline CVA no. (\%) & $2(2)$ & $2(2)$ & 1 \\
Superficial STWI no. (\%) & $3(3)$ & $2(2)$ & .7 \\
Deep STWI no. (\%) & $1(1)$ & 0 & .3 \\
Re-catheterization no. (\%) & $1(1)$ & $2(2)$ & .6 \\
Reoperation no. (\%) & $2(2)$ & $1(1)$ & .6 \\
LOS (d) & & & .8 \\
$\begin{array}{l}\text { Median } \\
\text { IQR }\end{array}$ & 6 & 6 & .002 \\
Readmission no. (\%) & $9-8$ & $5-7$ & \\
30-d mortality no. (\%) & 0 & 0 & 0 \\
\hline
\end{tabular}

$C V A$, Cerebrovascular accident; STWI, sternal wound infection; $L O S$, length of stay; $I Q R$, interquartile range.

process of delegating cases to the trainees. With excellent patient care being our primary goal, we tried to identify a low-risk group in which the inefficiencies related to the residents being the primary operators would not affect the postoperative outcomes.

The bias of directing more complicated cases to the attending is further suggested by the remarkable difference in the number of 30-day readmissions, with the attending group having 9 such events compared with no readmissions in the resident group. Although the 2 groups superficially appear similar, the attending group clearly included more complicated patients whose care required further hospitalizations after the initial discharge.

Despite longer operative, $\mathrm{CPB}$, and $\mathrm{ACC}$ times in the resident group, clinical outcomes were similar. Although there is ample evidence in the literature that longer operations lead to more complications and worse outcomes, our analysis suggests that in a carefully selected group of patients, these effects can be mitigated, thus making it possible to provide the trainees with an excellent operative educational experience, without sacrificing clinical outcome quality. However, it should be stressed that the low event rate of some of these negative outcomes may not be detected in our study; it is possible that with a larger patient cohort, differences in complication rates between the 2 groups may have surfaced. ${ }^{14}$

Although there was bias in the case selection, with lower STS score cases directed to the residents, we never attempted to allow a resident to perform an entire high complexity case with no attending involvement. Such cases may still be excellent vehicles for resident education by allowing the resident to perform specific steps (opening a redo sternotomy, sewing in a patch on a postinfarction ventricular septal defect, or finding coronary targets on a hostile epicardium) or general steps that do not prolong pump time or ischemia time (cannulating, harvesting conduits), but they require very active attending surgeon involvement and are generally not safe to be delegated to the resident as a skin-to-skin case.

This study reinforces the fact that there is a cost to educating residents. Academic cardiac surgeons must spend more hours in the hospital when resident training in the operating room is part of their teaching responsibilities. Yet, the government-sponsored insurers do not have any provisions, such as a procedure code modifier, that direct more federal funds to the centers that provide this invaluable service to future generations of surgeons, leaving it up to the individual institutions and departments to recognize the contribution to resident education by internally redirecting funds to the surgeons who provide this service.

We recognize that we could have included more cases in our sample had we relaxed the "skin-to-skin" rule. However, we thought that this would open the door to multiple interpretations as to what it means for a resident to "do the case." We certainly believe that although a skin-to-skin case is the culmination of the residents' experience, the bulk of their training comes from many more cases that residents are involved in during their training, which are split between the attending and the resident.

\section{Study Limitations}

There are several limitations to this study that may render our conclusions not applicable to other clinical settings. First and foremost, our effort to provide residents with superb training is supported by the institution, with nursing and ancillary staff willing and expected to work late into the day and accept the inefficiencies associated with our training philosophy. One may also argue that we have not looked at the specific issue of resident autonomy, because in all the resident cases the attending surgeon was always present for the critical parts of the operation, as recommended by the Commonwealth of Massachusetts Department of Health and mandated by our institutional policy.

Another limitation is the very nature of our comparison groups: We are comparing outcomes of a group of 8 residents with those of a single attending physician. Evaluating a more heterogeneous group of surgeons would have certainly added more power to our conclusions, but unfortunately we did not have the level of detailed data required for such an analysis from other staff members in our group. In addition, we acknowledge that the statistical power to detect a modest but important difference in poor outcomes is limited by our sample size $(\mathrm{n}=200)$. We further acknowledge that no conclusions can be made about an individual resident's performance given the relatively small number of cases done by each trainee.

Last, but certainly not least, we are very fortunate to have in our ranks a highly selective group of residents who come from our general surgery program and other premier training 
programs in the United States. Their attitude toward patient care, attention to detail, and drive to excel are second to none. Whether this aggressive attitude toward resident participation in the operating room can be applied across all training programs is certainly up for debate.

\section{CONCLUSIONS}

Resident training and education are complicated endeavors that have to be approached in a systematic way. They require a significant mental frame and time commitment from the attending staff, which may not translate into commensurate financial compensation. Still, the academic attending physician needs to approach the training strategy for each case with the same intensity and thoroughness as the preoperative clinical strategy (eg, choice of incision, conduits, types of prostheses). Despite all the external factors that are often used as excuses to justify the more limited operative experience that residents receive today when compared with years past, we think that with a systematic approach to training that includes careful preoperative planning, insistence on intraoperative technical excellence, and meticulous myocardial protection and postoperative care, current residents can receive hands-on training that is equal to, if not better than, the training that previous generations of cardiac surgeons have received.

\section{Webcast}

You can watch a Webcast of this AATS meeting presentation by going to: https://aats.blob.core.windows.net/media/ 17AM/2017-05-03/RM302-304/05-03-17_Room302-304_ 0818_Tolis.mp4.

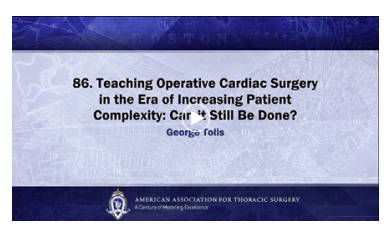

\section{Conflict of Interest Statement}

Authors have nothing to disclose with regard to commercial support.

\section{References}

1. Moffatt-Bruce SD, Ross P, Williams TE. American board of thoracic surgery examination: fewer graduates, more failures. J Thorac Cardiovasc Surg. 2014;147: 1464-9.

2. Ohye RG, Jaggers JJ, Sade RM. Must surgeons in training programs allow residents to operate on their patients to satisfy board requirements? Ann Thorac Surg. 2016;101:18-23.

3. Vaporciyan AA, Reed CE, Erikson C, Dill MJ, Carpenter AJ, Guleserian KJ, et al Factors affecting interest in cardiothoracic surgery: survey of North American general surgery residents. J Thorac Cardiovasc Surg. 2009;137:1054-62.

4. Chitwood WR, Spray TL, Feins RH, Mack MJ. Mission critical: thoracic surgery education reform. Ann Thorac Surg. 2008;86:1061-2.

5. Bakaeen FG, Dhaliwal AS, Chu D, Bozkurt B, Tsai P, LeMaire SA, et al. Does the level of experience of residents affect outcomes of coronary artery bypass surgery? Ann Thorac Surg. 2009;87:1127-34.
6. Haan CK, Milford-Beland S, O’Brien S, Mark D, Dullum M, Ferguson TB, et al. Impact of residency status on perfusion times and outcomes for coronary artery bypass graft surgery. Ann Thorac Surg. 2007;83:2103-10.

7. Raval MV, Wang X, Cohen ME, Ingraham AM, Bentrem DJ, Dimick JB, et al. The influence of resident involvement on surgical outcomes. J Am Coll Surg. 2011;212:889-98.

8. Baskett RJF, Kalavrouziotis D, Buth KJ, Hirsch GM, Sullivan JAP. Training residents in mitral valve surgery. Ann Thorac Surg. 2004;78:1236-40.

9. Yount KW, Yarboro LT, Narahari AK, Ghanta RK, Tribble CG, Kron IL, et al. Outcomes of trainees performing coronary artery bypass grafting: does resident experience matter? Ann Thorac Surg. 2017;103:975-81.

10. Murzi M, Caputo M, Aresu G, Duggan S, Angelini GD. Training residents in offpump coronary artery bypass surgery: a 14-year experience. J Thorac Cardiovasc Surg. 2012;143:1247-53.e1.

11. Soppa G, Yates M, Viviano A, Smelt J, Valencia O, van Besouw JP, et al. Trainees can learn minimally invasive aortic valve replacement without compromising safety. Interact Cardiovasc Thorac Surg. 2015;20:458-62.

12. Caputo M, Reeves BC, Rogers CA, Ascione R, Angelini GD. Monitoring the performance of residents during training in off-pump coronary surgery. J Thorac Cardiovasc Surg. 2014;128:907-15.

13. Caputo M, Chamberlain MH, Ozalp F, Underwood MJ, Ciulli F, Angelini GD Off-pump coronary operations can be safely taught to cardiothoracic trainees. Ann Thorac Surg. 2001;71:1215-9.

14. Brown WR, Moody DM, Challa VR, Stump DA, Hammon JW. Longer duration of cardiopulmonary bypass is associated with greater numbers of cerebral microemboli. Stroke. 2000;31:707-13.

Key Words: operative teaching, resident education, skinto-skin

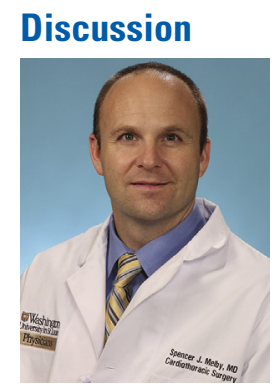

Dr S. Melby (St Louis, Mo). Dr Tolis, you and your colleagues are to be congratulated for your efforts in training the next generation of cardiothoracic surgeons and your courage in allowing them to do so, and publishing your results. At my institution, Washington University in St Louis, we also have between 9 and 12 residents at any given time at various stages in their training. Clearly, training residents today is very different and we have different obstacles than what were encountered in past years. Limitations in work hours, like you mentioned, more complex patients, and a change in the perception of what a resident's role should be by the public are all real challenges we encounter in training residents today.

Despite these challenges, you have demonstrated equivalent survival and hospital length of stay and improved bounce-back rates in the face of longer operative times, including longer crossclamp and bypass times in a group of patients who had their surgery done by the residents. This gives training surgeons confidence that we can patiently allow residents to do cases safely, with the caveat being that these need to be selected cases that are appropriate for the resident, as you mentioned.

I have a couple of questions that might help us understand how you and your colleagues dealt with the intraoperative challenges that inevitably arise while training residents. How many 
of you and your colleagues participated in the study and how many residents did cases that were counted as skin-to-skin resident cases?

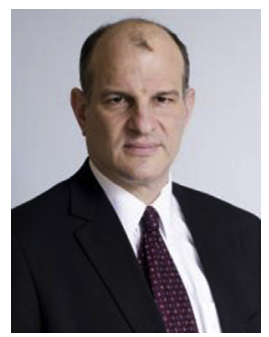

Dr Tolis. The attending cases were done by me, so it's a single surgeon study. We have 3 residents every year, and we don't distinguish between cardiac and thoracic; they all receive the same cardiac training. Obviously, the thoracic residents have to do less numbers, but when I am working with a chief resident it does not make a difference to me if this is a thoracic track or a cardiac track. So between 9 and 12 residents were exposed to these cases. These were done over a 2.5-year period. So 1 attending, 9 to 12 residents.

Dr Melby. Clearly, there are situations that would arise in the operating room where it wasn't practical or safe to allow the residents to complete the entire case. How would the surgeon determine that this was a time to take over the case and how often did that happen? I think we are to understand that those patients who had changed hands during the case were not counted in the study or evaluated. Did those patients do as well as those who were in the study?

Dr Tolis. As you said, these patients are not included in the study. If, for example, I started a case and I realized that it is an easier case than I anticipated or that the targets looked good and that the resident can do a case, you switch back to letting the resident do the case. If, on the other hand, you decide that it is something like you had not anticipated, for example, you open someone and they have uremic adhesions and you can't distinguish anything on the surface of the heart, and then you have to find the targets and so on, then you take the case over.

I think that a statement that people make, which is sort of more of a macho statement but has no room in the operating room, like there is nothing that you can break that I can't fix, I think that's nonsense. The most important thing to do is anticipate 2 or 4 steps down the road a complication that may happen because of something that is starting now and either stop that and direct the resident better or take the case over if you think that the resident cannot move back. I think that the most important thing is not to fix a complication but to prevent it, like I said, 2 or 3 steps back.

Dr Melby. My last question deals with those residents who are not yet ready to do a full case skin-to-skin. Although not in this study, would you briefly comment on what your group does to allow these residents a graded responsibility so they can develop the skills and techniques to do an entire case? Again, congratulations on training residents. It's a different set of skills needed and a different level of patience needed to allow residents to do cases like you are describing.
Dr Tolis. Obviously, this is a very gradual process. You start by teaching someone basic things where time doesn't matter, for example, opening the bone or taking down a mammary or even cannulating. I think it is important to make the transition to help the resident do enough of the case so that they can start counting it toward their experience, and I think that if they complete the initial steps prebypass with you helping them and then you let them do a portion of the operation, for example, 2 of the 4 grafts if they are taking too long for these 2 grafts, and then help them decannulate and come off bypass, that's the next transition where they can actually count it as a CABG 1 or a CABG 2 versus a CABG 5 that was the actual operation.

In terms of valvular surgeries, I find an operation that you can control is much easier to teach, such as an AVR. MVR is a bit tricky because it gets pretty crowded on the surgeon's side if you are trying to show someone how to do it. But again, with a graduated responsibility process you can help a resident learn how to do these operations.

We hear about how the resident needs to be trained on modern technology so that the field stays relevant and so on. I think it is very important. But I think what is also extremely important for the field to stay relevant is for residents to learn how to do these operations that have worked extremely well for the past 40 years.

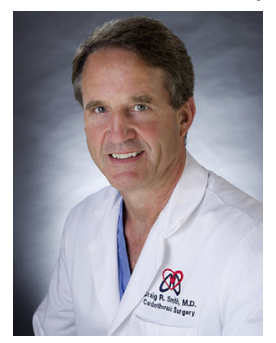

Dr C. Smith (New York, NY). I think it is a significant weakness of the study that it is a single attending and a group of residents. It compares high variability (the residents) with low variability. I would be interested to know why only 1 attending was included.

Dr Tolis. I have personally kept a detailed log over the years of what I have done, what I have let a resident do, and to have this information as to exactly what each resident did, you need a database that is as comprehensive as this, and I could not get similar information from other colleagues.

Dr Smith. But you are making an admirable attempt to compare 2 groups. All you needed was a few more attendings to make it a real study.

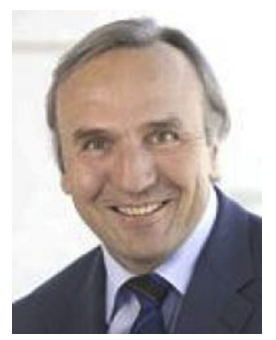

Dr F. Mohr (Leipzig, Germany). We do control all our surgeons, and if you compare 15 trained surgeons at my institution, you will find a variety that is almost close to your residents and some surgeons who work very slowly. It's a good idea to do this study, but there is a major difference in experienced surgeons in terms of crossclamp time and CPB time. So I would also recommend to look at that larger scale. 